\title{
Synchronous Teacher Training in India: A Study of Perceptions and Satisfaction of the Participants
}

\author{
Kalpana Kannan and Krishnan Narayanan
}

\begin{abstract}
This paper describes the methodology used for training a large number of engineering college teachers using synchronous technology in India. The goal of these synchronous workshops is to improve the quality of teaching in higher education by training a large number of teachers in a short time. The paper presents the survey results of fourteen workshops conducted in synchronous distance mode from the year 2009 to 2013. From the survey, we found that a large number of young teachers, female teachers and teachers in rural colleges are benefitting from the workshops. Even though the participants attended these workshops in the distance mode, the survey results showed that the participants' perceptions on the quality of instruction, workshop content and quality of audio-video transmission were good. On an average about $90 \%$ of the respondents rated their experience as excellent or good. We also found that after scaling up the number of participants from 1000 to 10000 teachers per workshop, there was a slight dip in the rating, but the overall level of satisfaction of the participants was not much affected due to scale up.
\end{abstract}

Index Terms-ICT enabled workshops, teacher training, synchronous distance education, descriptive statistics, perception, satisfaction.

\section{INTRODUCTION}

Education and knowledge have a powerful impact on human capital formation, and teachers play an important role in building the human capital. Teachers have to satisfy the growing demand for better skills and employability of their students. Therefore, present day teachers need more opportunities than ever before for life-long learning. Today, there is a crisis in teaching profession. Most developing countries around the world have shortage of good teachers. We need better teachers and in large numbers to cater to the growing needs of the knowledge based society. One of the ways to strengthen the teaching profession is to impart professional development through Information and Communication Technology (ICT). There are many advantages of ICT enabled education that cannot be achieved by the conventional mode. For example, ICTs reduce the opportunity cost, travel cost, can reach out to different socio-economic groups in remote areas and in a short span of time.

Although the importance of teachers is emphasized in many international reports [1]-[3], the resources allocated to teacher training activity is inadequate and the opportunities are few. The attention given to teachers' education and their

Manuscript received January 10, 2014; revised April 8, 2014.

The authors are with the Department of Humanities and Social Sciences, Indian Institute of Technology Bombay, Mumbai, India (e-mail kalpanak@it.iitb.ac.in,knn@iitb.ac.in) continuing professional development has in many cases lagged behind compared to that given to other areas of the education system. According to the UNESCO report on higher education in some countries, teachers can expect one week's in-service professional development once in five to ten years [4]. Therefore, it is important to significantly scale-up the training activity for teachers in most developing countries. One of the ways to scale-up the professional development activity is through ICT [5].

ICT enabled education is an emerging field. It offers both opportunities and challenges for researchers and educationalists. It fulfills various needs of the society which is otherwise difficult to achieve through the conventional education. Literature shows that many universities across the world have adopted ICT enabled education for higher education, skill development and professional development. Research shows that ICT enabled education has a positive impact on teachers and learners [6], [7]. Some of the developing countries have adopted ICT tools to improve the gross enrollment ratio in higher education [8], teacher training [4] and distance education through television and radio [9]. The application of ICT has also revolutionized and enriched education and skill development in the rural areas [10]. People with disabilities [11], [12], and women who could not earlier participate in learning process due to socio-cultural barriers now can [8]. Thus, ICTs are powerful tools for extending educational opportunities outside the boundaries of traditional classrooms. With the help of ICT, one can reach out to a larger population - rural population, women, minority groups, and persons with disability, elderly, and those who are unable to participate in the learning activity because of cost or lack of time.

In India, there has been a rapid expansion of institutions of higher education since independence in 1947. The number of universities and colleges increased from 20 and about 500 in 1947 to approximately 700 and 20,000 respectively today [13]. Every year about 1 million undergraduate students graduate from various engineering disciplines [14]. There are about 5000 engineering colleges and about 200,000 teachers teach in these colleges [14]. Unfortunately, the quality of skill sets imparted in undergraduate education is low and many students do not find appropriate jobs.

The quality of engineering education has suffered due to a variety of reasons: 1) the sudden expansion of colleges has led to a shortage of qualified and experienced teachers, 2) low salary in the teaching profession has further added to the shortage 3) students are unmotivated, and 4) lack of infrastructure in colleges [5]. The biggest resource crunch in higher technical education today is the non-availability of experienced and qualified teachers [15]. To raise the level of engineering education in the country is a national level 
problem, for which there is no one solution.

In order to train a large number of engineering college teachers in the country, the 'Train 10000 Teachers (T10KT)' project at the Indian Institute of Technology (IIT) Bombay (from now on referred to as IIT Bombay team) uses ICT to conduct workshops [5]. This initiative was started in the year 2009, under the National Mission on Education through Information and Communication Technology (NMEICT) [16], Ministry of Human Resource Development, Government of India. These workshops are conducted in synchronous distance mode. The lectures are transmitted live from a single location (IIT Bombay) and 50-80 participants located at 150-200 different geographical locations (Remote centres) attend these workshops in synchronous remote classrooms. Initially, it started with 1000 teachers per workshop and after its success it was scaled up to 10,000 teachers per workshop.

This paper presents the descriptive statistics of workshops conducted in the synchronous distance mode from the year 2009 to 2013 . We have used the online survey method to collect data from the participants and have analysed to find out demography of participants, participants' perceptions and levels of satisfaction. The study was conducted to answer the following research questions: 1) Whether the synchronous teacher training programme was reaching out to the target group? 2) What were the perceptions and satisfaction levels of the participants of synchronous mode teacher training workshops?

\section{LITERATURE REVIEW}

Literature shows that in the last decade, many countries have used ICT for teacher training. In a qualitative study [17] on Chinese language teachers, the authors found that collaborative learning proved to be an important component in training and in supporting learning community in a cyber environment. In a study conducted in Ethiopia, Adem [18] found that teacher training through ICT at all levels had high dropout, lack of incentive, accreditation and support. Young and Lewis [19] studied the perceptions of pre-service teachers towards a training programme delivered at a distance. The authors found that overall the teachers had a positive response to distance education. Moeini [20], Zhang and Hung [21] conducted studies on use of ICTs for school teacher training and found improvement in teaching skills. They also found that ICTs can offer interactive and effective learning environments.

In India, the need to use technology in education started mainly to reach out to a larger population and also to improve the quality of education at all levels. Arora and Pandey [22] had analysed the effectiveness and usefulness of distance education/ training for a large number of school teachers, conducted by the National Council for Educational Research and Training (NCERT) in collaboration with Indira Gandhi National Open University [23]. According to the authors, the use of interactive video technology was found to be suited for training of teachers especially in remote parts of the country; they also suggested that the training programme through distance mode should become a frequent feature to make it cost-effective. Bhattacharya [24] reviewed some of the technology enhanced initiatives such as, National Programme on Technology Enhanced learning (NPTEL), use of education satellite (EDUSAT), virtual classrooms and virtual laboratory undertaken by Government of India to improve the quality in engineering education in India.

We found that most of the studies were done on school teachers using asynchronous ICT tools. To the best of our knowledge there are no studies done so far in India for a large scale synchronous teacher training. This paper contributes to the growing literature on the use of ICT for higher education.

\section{TRAining Methodology}

IIT Bombay team conducts two-week workshops during summer and winter vacation for engineering college teachers. IIT Bombay acts as the hub. It uses ICT enabled process involving both synchronous and asynchronous modes to reach out to a large number of engineering college teachers. The lecture transmission and live interaction take place through distance mode using Internet based software called AVIEW [25], at selected remote centres across the country [5]. The participating teachers attend at a remote centre close to their own college, and also attend tutorials and lab sessions conducted in the same remote centre.

The workshop is conducted in two parts: Coordinators' workshop and the main workshop. Two months prior to the main workshop, IIT Bombay team invites teachers from various engineering colleges for a one-week Coordinators' workshop [5]. These Coordinators help conduct the main workshop at the respective remote centres. During the main workshop, the lectures are transmitted live from IIT Bombay and the laboratory sessions are conducted locally at the remote centres. The interactions happen through synchronous mode (AVIEW and chat) and asynchronous mode (discussion forum in Learning Management System 'Moodle' and email). There are about 300 remote centres in the country and typically about $150-200$ remote centres participate in each workshop.

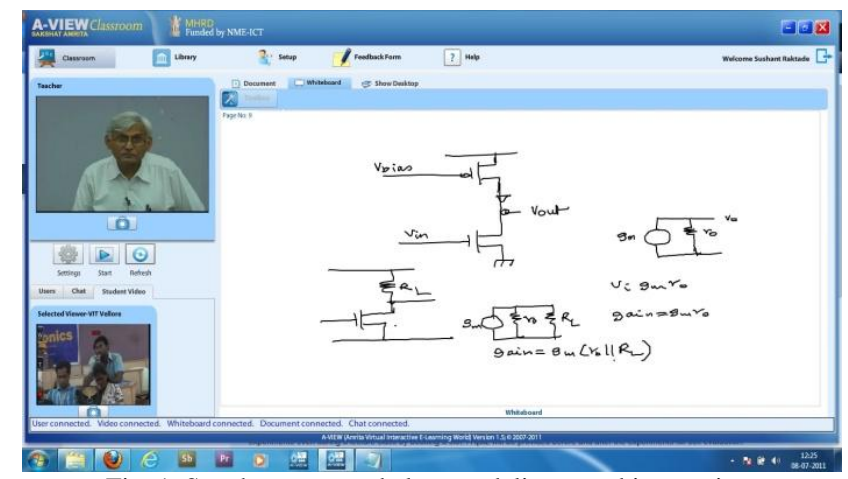

Fig. 1. Synchronous mode lecture delivery and interaction.

During the main workshop, every remote centre accommodates about 50 to 80 teachers. Every remote centre has two Coordinators - a Remote Centre Coordinator (RCC) and a Workshop Coordinator (WSC). The RCC is nominated by the head of the institution and is responsible for the overall management and smooth conduct of every workshop. The Workshop Coordinator is an experienced faculty member in the subject to be taught in the workshop and is responsible for solving doubts of the participants during the main workshop. 
All lectures and tutorial sessions are recorded during the workshop. The final edited audio-visual contents, along with other course material are released under open source on the workshop website T10KT [26] to the teaching-learning community.

\section{SYNCHRONOUS MODE WORKSHOPS}

Since December 2009, fourteen workshops have been conducted under this programme on various subjects. About 36,500 teachers have participated in these workshops and about 20,000 teachers have given their feedback on the conduct of the workshops. The participants for these workshops are spread across the country as the remote centres are located at various geographical locations. Synchronous delivery of lectures and interactions happen through an internet based software. Fig. 1 gives the view of the synchronous classroom. In Phase I of the project (2009-2012), ten workshops were conducted and about 11,000 teachers had participated. The target for each workshop was 1000 teachers per workshop. The pilot workshop was conducted in Computer programming in December 2009, with 22 remote centres in the country. The number of remote centres in the country is about 300 today.

In Phase II of the project (2012-2015), the target for each workshop is 10,000 teachers. Since there are about 300 remote centres in the country, this number is easily achievable if every remote centre accommodates about 40 to 60 participants in their respective remote centres. In Phase II, so far four workshops have been conducted and about 25,500 teachers have participated. The statistics on workshops conducted from year 2009 to 2013 is given in Table I.

\section{RESEARCH METHODOLOGY}

The objectives of our study were to find if the training programme was reaching out to the target group and to find the perceptions and satisfaction levels of the participants. As the number of participants was large and geographically scattered, we adopted online survey method to answer the research questions.

\section{A. Data collection}

An instrument was developed to collect data on demography and to measure other variables in the study.

The questionnaire was first tested in the pilot workshop and some items were modified and re-worded. After every workshop, online questionnaire was posted on the workshop learning management system 'Moodle' and the participants were given ten days time to fill the questionnaire. Information on gender, age group and location of colleges of the participants in rural or urban areas were collected through the questionnaire. Other items to measure participants' perceptions on instructor, content, audio and video quality were measured using a five-point Likert scale from 'Strongly disagree $=1$ ' to 'Strongly agree $=5$ '. The overall satisfaction was measured using the scale 'Poor $=1$ ', 'Satisfactory $=2$ ', 'Good $=3$ ' and 'Excellent $=4$ '.

\section{B. Sample Size}

We had a fairly large sample size in every workshop, on an average about $54 \%$ of the participants responded to our online questionnaire. The sample size for the initial workshops were about 450 and later as the workshop scaled up to ten times the sample size also increased to about 3700 . Table II gives the details on sample size.

\begin{tabular}{|c|c|c|c|c|c|c|}
\hline Workshop no. & Date & Workshop & Participants & $\begin{array}{l}\text { Remote } \\
\text { centres }\end{array}$ & $\begin{array}{l}\text { Cities/ } \\
\text { Towns }\end{array}$ & Colleges \\
\hline 1 & Dec 2009 & Computer Programming (pilot) & 637 & 22 & 204 & 70 \\
\hline 2 & July 2010 & Computer Programming & 641 & 30 & 218 & 130 \\
\hline 3 & Dec 2010 & Database Mang. Sys. (DBMS) & 1022 & 32 & 158 & 161 \\
\hline 4 & June 2011 & Thermodynamics & 779 & 31 & 248 & 424 \\
\hline 5 & June 2011 & Basic electronics & 1267 & 38 & 401 & 429 \\
\hline 6 & Nov 2011 & Software Dev. Technique & 773 & 21 & 113 & 300 \\
\hline 7 & Dec 2011 & Heat Transfer & 735 & 28 & 377 & 327 \\
\hline 8 & Dec 2011 & Solar PV & 930 & 35 & 245 & 350 \\
\hline 9 & Feb 2012 & $\begin{array}{l}\text { Writing effective conference } \\
\text { papers* }\end{array}$ & 3144 & 35 & 373 & 1150 \\
\hline 10 & June 2012 & $\begin{array}{l}\text { Computational fluid dynamics } \\
\text { (CFD) }\end{array}$ & 1253 & 47 & 275 & 561 \\
\hline 11 & June 2012 & Introduction to research methods & 7506 & 168 & 560 & 2000 \\
\hline 12 & Dec 2012 & Engineering Thermodynamics & 4759 & 167 & 701 & 1209 \\
\hline 13 & Feb 2013 & $\begin{array}{l}\text { Research Methods in Education } \\
\text { Technology * }\end{array}$ & 5755 & 194 & 159 & 1363 \\
\hline 14 & May 2013 & DBMS & 7423 & 246 & 801 & 1121 \\
\hline
\end{tabular}

Note: All workshops were for two-weeks duration except for the ones marked * were two-day workshops

\section{Demography and Location of Participants}

For all the workshops, demography and location of the participants is tabulated in Table II. We observed that, on an average, the workshops had a large number of female participants (about 40\%); the only exceptions were the mechanical engineering workshops, where the number of female participants was only about $12 \%$. Majority of the participants, about $84 \%$ were below 40 years of age and only about $16 \%$ were above 40 years. On an average about $40 \%$ of the participants belonged to colleges located in rural areas and about $60 \%$ were from colleges situated in urban areas. 
TABLE I: DEMOGRAPHY AND LOCATION OF PARTICIPANTS

\begin{tabular}{|c|c|c|c|c|c|c|c|c|}
\hline \multirow[t]{2}{*}{ Workshop } & \multirow{2}{*}{$\begin{array}{l}\text { Sample } \\
\text { N }\end{array}$} & \multicolumn{2}{|c|}{ Gender (in \%) } & \multicolumn{3}{|c|}{ Age group (in \%) } & \multicolumn{2}{|c|}{ Location (in \%) } \\
\hline & & Male & Female & 23-30 & $31-40$ & $\begin{array}{l}\text { above } \\
40\end{array}$ & Urban & Rural \\
\hline Computer Programming (pilot) & 463 & 48 & 52 & 65 & 29 & 6 & 65 & 35 \\
\hline Computer Programming & 448 & 51 & 49 & 68 & 26 & 6 & 58 & 42 \\
\hline Database Mang. Sys. (DBMS) & 710 & 53 & 47 & 65 & 29 & 6 & 58 & 42 \\
\hline Thermodynamics & 686 & 88 & 12 & 46 & 38 & 18 & 55 & 45 \\
\hline Basic electronics & 1029 & 55 & 45 & 57 & 32 & 11 & 56 & 44 \\
\hline Software Dev. Technique & 502 & 63 & 37 & 62 & 33 & 5 & 57 & 43 \\
\hline Heat Transfer & 707 & 88 & 12 & 43 & 41 & 16 & 55 & 45 \\
\hline Solar PV & 845 & 69 & 31 & 42 & 40 & 18 & 53 & 47 \\
\hline $\begin{array}{l}\text { Writing effective conference } \\
\text { papers* }\end{array}$ & 1666 & 56 & 44 & 59 & 33 & 8 & 58 & 41 \\
\hline $\begin{array}{l}\text { Computational fluid dynamics } \\
\text { (CFD) }\end{array}$ & 1001 & 87 & 13 & 43 & 43 & 14 & 62 & 38 \\
\hline Introduction to research methods & 4173 & 60 & 40 & 49 & 39 & 12 & 57 & 43 \\
\hline Engineering Thermodynamics & 2981 & 87 & 13 & 57 & 31 & 13 & 51 & 49 \\
\hline $\begin{array}{l}\text { Research Methods in Education } \\
\text { Technology* }\end{array}$ & 1506 & 60 & 40 & 52 & 38 & 10 & 59 & 41 \\
\hline DBMS & 3703 & 53 & 47 & 63 & 32 & 5 & 57 & 43 \\
\hline
\end{tabular}

\section{Data Analysis}

After every workshop, participants' perceptions on quality of instruction, quality of audio and video transmission, usefulness of workshop content and overall satisfaction was measured with the help of the questionnaire. The percentages of respondents who agreed/ disagreed with the statements were analysed. We observed that there were only a small percentage of respondents who strongly disagreed with the statements; therefore, we combined 'Strongly disagree' and 'Disagree' into one category for analysis.

\section{RESULTS AND DISCUSSION}

After analyzing the data we observed that these workshops are easily scalable. As it can be observed from the data given in Table I, the workshops could be scaled up ten times in about three years. The number of remote centres was scaled up from about 30 to 300 centres and the number of participants went up from about 640 to about 7400 in three years.

One of the objectives of these workshops is to reach out to people who are generally left out. People who have fewer opportunities are female teachers and teachers teaching in colleges located in rural and remote areas of the country.

\section{A. Outreach and Inclusion}

The gender distribution is given in Fig. 2. We observe that except for mechanical engineering courses, most of the workshops had about $40 \%$ female participants. In mechanical engineering courses (workshop no. 4, 7, 10 and 12) the percentage of female participants was about $12 \%$. This could be because the number of female studying mechanical engineering in the country is few. One of the reasons cited for a large number of female participation in these workshops was proximity of the remote centres. Some of the female participants told us that because of the proximity of the remote centre it was easier for them to attend the workshops. They did not have to leave their families for a long period of time to attend the workshops.

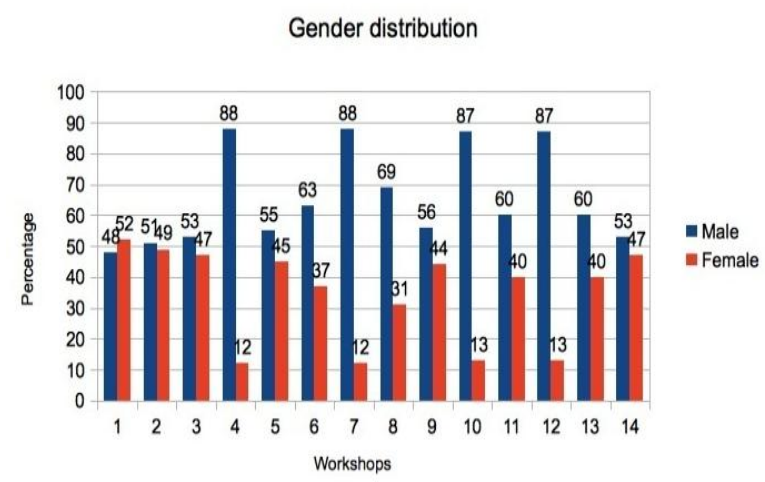

Fig. 2. Gender distribution.
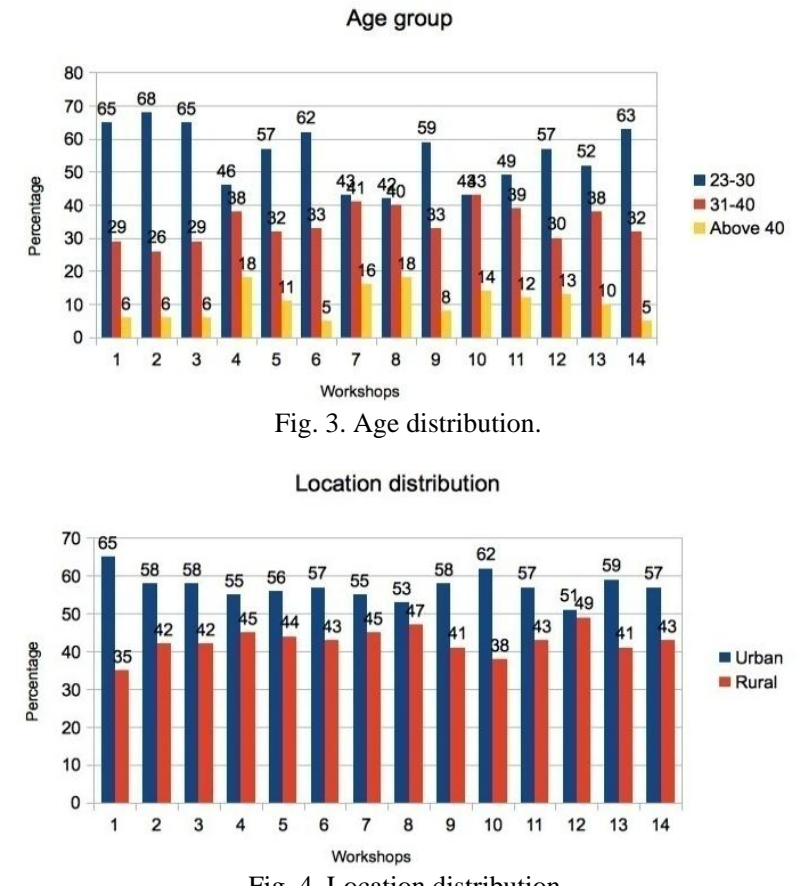

Fig. 4. Location distribution.

The age distribution is given in Fig. 3. From the data we observe that majority of the participating teachers (about 
$50 \%$ ) were in the age group 23 to 30 years and about $16 \%$ of the teachers were above 40 years of age. The benefits of the workshops would be more if the majority of teachers are young as they can experiment with new ideas and implement it in their classroom teaching.

In all the workshops, about $40 \%$ of teachers came from colleges located in rural areas. The location distribution is given in Fig. 4. One of the advantages of technology-enabled workshops is reaching out to remote places in the country. This has been demonstrated in these workshops. Thus, after analyzing the data we can conclude that synchronous mode teacher training workshops is reaching out to a large number of young teachers, female teachers and teachers in rural colleges. Therefore, we can conclude that the synchronous mode teacher training programme is reaching out to the target group.

\section{B. Perception and Level of Satisfaction}

The feedback received from the participants show that about $90 \%$ of the respondents agreed or strongly agreed that the quality of instruction of the workshops were good (see Table III.)

\begin{tabular}{|c|c|c|c|c|c|}
\hline Statement & Workshop no. & $\begin{array}{l}\text { Strongly agree } \\
\text { (in \%) }\end{array}$ & $\begin{array}{l}\text { Agree } \\
\text { (in \%) }\end{array}$ & $\begin{array}{c}\text { Neutral } \\
\text { (in \%) }\end{array}$ & $\begin{array}{c}\text { Disgree } \\
\text { (in \%) }\end{array}$ \\
\hline \multirow{14}{*}{$\begin{array}{l}\text { Instructor used innovative teaching methods } \\
\text { and was able to explain difficult concepts }\end{array}$} & 1 & 41 & 52 & 5 & 2 \\
\hline & 2 & 31 & 60 & 8 & 1 \\
\hline & 3 & 37 & 57 & 5 & 1 \\
\hline & 4 & 42 & 48 & 7 & 3 \\
\hline & 5 & 22 & 65 & 10 & 3 \\
\hline & 6 & 25 & 59 & 12 & 4 \\
\hline & 7 & 42 & 52 & 5 & 1 \\
\hline & 8 & 30 & 60 & 8 & 2 \\
\hline & 9 & 35 & 55 & 8 & 2 \\
\hline & 10 & 32 & 55 & 11 & 2 \\
\hline & 11 & 25 & 60 & 12 & 3 \\
\hline & 12 & 41 & 50 & 8 & 1 \\
\hline & 13 & 25 & 60 & 12 & 3 \\
\hline & 14 & 40 & 50 & 8 & 2 \\
\hline \multicolumn{6}{|c|}{ TABLE IV: PERCEPTION ON QUALITY OF AUDIO AND VIDEO TRANSMISSION } \\
\hline Statement & Workshop no. & $\begin{array}{l}\text { Strongly agree } \\
\quad(\text { in } \%)\end{array}$ & $\begin{array}{l}\text { Agree } \\
\text { (in \%) }\end{array}$ & $\begin{array}{l}\text { Neutral } \\
\text { (in \%) }\end{array}$ & $\begin{array}{l}\text { Disgree } \\
(\text { in } \%)\end{array}$ \\
\hline \multirow{14}{*}{$\begin{array}{l}\text { The quality of audio and video transmission } \\
\text { was good }\end{array}$} & 1 & 35 & 56 & 8 & 1 \\
\hline & 2 & 25 & 60 & 10 & 5 \\
\hline & 3 & 32 & 53 & 10 & 5 \\
\hline & 4 & 32 & 57 & 8 & 3 \\
\hline & 5 & 17 & 62 & 12 & 9 \\
\hline & 6 & 25 & 59 & 11 & 5 \\
\hline & 7 & 38 & 54 & 7 & 1 \\
\hline & 8 & 32 & 56 & 9 & 3 \\
\hline & 9 & 30 & 52 & 12 & 5 \\
\hline & 10 & 36 & 52 & 9 & 3 \\
\hline & 11 & 25 & 58 & 13 & 4 \\
\hline & 12 & 30 & 52 & 12 & 6 \\
\hline & 13 & 32 & 51 & 9 & 8 \\
\hline & 14 & 50 & 41 & 8 & 1 \\
\hline \multicolumn{6}{|c|}{ TABLE V: PERCEIVED USEEFULNESS OF WORKSHOP CONTENT } \\
\hline Statement & Workshop no. & $\begin{array}{l}\text { Strongly agree } \\
\quad \text { (in \%) }\end{array}$ & $\begin{array}{l}\text { Agree } \\
\text { (in \%) }\end{array}$ & $\begin{array}{l}\text { Neutral } \\
\text { (in \%) }\end{array}$ & $\begin{array}{c}\text { Disgree } \\
\text { (in \%) }\end{array}$ \\
\hline \multirow{14}{*}{$\begin{array}{l}\text { The workshop content was useful and would } \\
\text { help in teaching }\end{array}$} & 1 & 37 & 52 & 10 & 1 \\
\hline & 2 & 36 & 55 & 8 & 1 \\
\hline & 3 & 45 & 50 & 4.5 & 0.5 \\
\hline & 4 & 38 & 58 & 3 & 1 \\
\hline & 5 & 28 & 65 & 6 & 1 \\
\hline & 6 & 35 & 55 & 8 & 2 \\
\hline & 7 & 41 & 53 & 4 & 2 \\
\hline & 8 & 40 & 55 & 3 & 2 \\
\hline & 9 & 37 & 56 & 6 & 1 \\
\hline & 10 & 59 & 31 & 8 & 2 \\
\hline & 11 & 20 & 70 & 9 & 1 \\
\hline & 12 & 35 & 56 & 8 & 1 \\
\hline & 13 & 28 & 58 & 12 & 2 \\
\hline & 14 & 50 & 45 & 4 & 1 \\
\hline
\end{tabular}


About $85 \%$ of respondents agreed or strongly agreed that the quality of audio and video transmission during the workshops was good. Some remote centres faced problems in the audio-video quality, because of low bandwidth or due to local technical set-up problem. From the data we observed that about $15 \%$ of the respondents were not satisfied with the quality of audio and video transmission. Therefore, it is recommended to improve the quality of audio and video transmission in the future workshops (see Table IV).

About $90 \%$ of the respondents agreed or strongly agreed that the workshop content was useful and would enable them to teach better. The respondents' feedback on usefulness of workshops is given in Table $\mathrm{V}$.

On an average, about $40 \%$ of the respondents said that their overall experience was excellent, about $50 \%$ said it was good, about $9 \%$ said it was satisfactory and less than $1 \%$ said it was poor (see Table VI). We also observed that after scaling up the number of participants in the workshops, there was a slight dip in the rating, but the overall level of satisfaction was not much affected. Thus, with the help of data we can say that technology helps to scale up without affecting the level of satisfaction of participants. The graph on overall satisfaction is given in Fig. 5.

TABLE VI: OVERALL SATISFACTION

\begin{tabular}{lllll}
\hline $\begin{array}{l}\text { Workshop } \\
\text { no. }\end{array}$ & $\begin{array}{l}\text { Excellent } \\
\text { (in } \%)\end{array}$ & $\begin{array}{l}\text { Good } \\
\text { (in \%) }\end{array}$ & $\begin{array}{l}\text { Satisfactory } \\
\text { (in } \%)\end{array}$ & $\begin{array}{l}\text { Poor } \\
\text { (in } \%)\end{array}$ \\
\hline 1 & 52 & 35 & 12 & 1 \\
2 & 43 & 52 & 5 & 0 \\
3 & 51 & 44 & 4.7 & 0.3 \\
4 & 47.7 & 44 & 8 & 0.3 \\
5 & 31 & 54.5 & 14 & 0.5 \\
6 & 36 & 56 & 7.4 & 0.6 \\
7 & 45 & 48 & 7 & 0 \\
8 & 49 & 44 & 6.7 & 0.3 \\
9 & 35.8 & 52 & 12 & 0.2 \\
10 & 36 & 49.4 & 14 & 0.6 \\
11 & 35 & 53.6 & 11 & 0.4 \\
12 & 33 & 48 & 18.2 & 0.8 \\
13 & 22 & 57.3 & 20 & 0.7 \\
14 & 40 & 47 & 12 & 1 \\
\hline
\end{tabular}

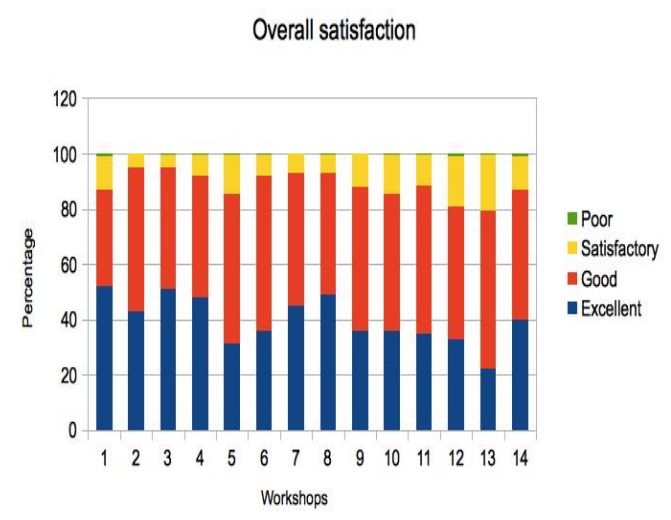

Fig. 5. Overall satisfaction.

\section{BENEFITS AND CHALLENGES OF SYNCHRONOUS DISTANCE MODE WORKSHOPS}

Some of the benefits and challenges of synchronous distance mode workshops are given in this section:

\section{A. Benefits}

Reduced cost: As the teachers attend the workshops in nearby remote centres, they do not have to travel long distances, hence, the travel cost is substantially reduced.

Scalable: The methodology is easily scalable. One can reach out to a large number of participants in a short time. This has been demonstrated in these workshops as from training 1000 teachers at a time, one could easily scale up to train 10,000 teachers at a time.

Uniform training: The methodology adopted provides uniform training by subject experts, irrespective of the location of the participants.

Highly interactive: The participants can interact with the faculty members in a synchronous mode through chat and live interactions or in an asynchronous mode through discussion forum and email.

Outreach and inclusion: One of the major advantages of synchronous mode workshop is that there is a large participation from people who are generally left out (women, teachers in rural and remote colleges). From the data we observe that this has been successfully achieved in the T10KT workshops.

Convenient: It is very convenient for the teachers to attend and benefit from these workshops, since these workshops are held during summer and winter vacation and the teachers do not have to travel long distances.

\section{B. Challenges}

Some of the challenges in the implementation of synchronous distance mode workshop are discussed below:

Technology issues: There is high dependence on technology in the synchronous mode workshops. As AVIEW was a new technology, there were some teething problems in the initial workshops. The quality of reception in some centres was low as the available bandwidth was less. Based on the user feedback, the AVIEW team made improvements in the software. The current software is user friendly and easy to use. Over the years, the quality of transmission through AVIEW has improved significantly [5].

Management and coordination: Managing a distance mode workshop needs a lot of planning and coordination. Lack of coordination and planning can become an obstacle to the programme. As there are about 300 remote centres in the country, the Remote Centre Coordinators and Workshop Coordinators play a very important role in local management and coordination at each centre. Therefore, one-week Coordinators' workshop at the hub is very important as this gives them an orientation on how to manage and coordinate the workshop in the distance mode. During the initial workshops, IIT Bombay team had to provide a lot of online support and troubleshooting guidelines to help solve some of the problems. In the subsequent workshops, as the Coordinators became familiar with the use of technology they were able to manage better. Thus, familiarity and experience in handling distance mode workshop are very important for the success [5].

\section{CONCLUSION}

In this paper, we discussed the methodology used for synchronous mode workshops for engineering college teachers in India. Through the survey, we found that a large number of young teachers, female teachers and teachers in 
rural colleges are benefitting from the workshops. The survey results also showed that the perceptions of the participants on the quality of instruction, workshop content and quality of audio and video transmission were good. However, about $15 \%$ of the participants were not satisfied with the quality of audio-video transmission, therefore, one of the recommendations and suggestions for future workshops is to improve the quality of audio and video transmission.

The survey showed that even though the participants attended these workshops in the distance mode, the overall experience of the participating teachers was very good. On an average about $90 \%$ of the respondents rated their experience as excellent or good. We also found that the level of satisfaction of the participants was not affected after scaling up the number of participants in the workshops. This is a good indicator for the workshop administration to plan for future workshops. A possible reason could be that even though the number of remote centres were increased, in each remote centre there were only about 40-60 participants, which is not very difficult to manage. We also observed that as the number of remote centres increased, the number of participants from rural colleges also increased, thus, reducing the gap between the urban and rural college teachers.

The future work includes both qualitative and quantitative analysis to assess the impact of these workshops on teachers and students. We have conducted a post workshop study after a gap of about six months. The preliminary findings are promising. The post workshop data shows that teachers with less teaching experience are likely to adopt new teaching methodology and make use of the new knowledge gained during the workshop.

We conclude that, effective use of ICT for teacher training can scale up the training activity significantly in the country and help in human capital formation. Such initiatives would not only help improve the quality of skill sets imparted in undergraduate education and employability of students, but also facilitate appropriate use of demographic dividend that India possesses.

\section{ACKNOWLEDGMENT}

The authors wish to thank Prof. D. B. Phatak for allowing them to carry out the survey. The financial support for conducting the workshop was made available by a grant from the National Mission on Education through ICT (NMEICT), Ministry of Human Resource Development, Government of India, New Delhi. The e-learning software AVIEW, also supported by NMEICT, was provided by the Amrita Vishwa Vidyapeetham, Kollam, Kerala.

\section{REFERENCES}

[1] UNESCO, World education report: Teachers and teaching in a changing world. Technical report, 1998.

[2] UNESCO, The Dakar framework for action: Education for all: Meeting our collective commitments. Technical report, 2000.

[3] OECD, Education policy analysis. Technical report, Centre forEducation Research and Innovation, Paris, 2001

[4] UNESCO, Teacher education through distance learning: Technology, Curriculum, Cost, Evaluation, Technical report, 2001.

[5] K. Kannan and K. Narayanan, "Post-Secondary Education and Technology - A Global Perspective on Opportunities and Obstacles to Development," ICT-Enabled Scalable Workshops for Engineering
College Teachers in India, Palgrave Macmillan, New York, 2012, pp. 127-146.

[6] P. Williams, "Lessons from the future: ICT scenarios and the education of teachers," Journal of education for teaching, vol. 31, no. 4, pp. 319-339, November 2005.

[7] C. K. Looi and D. Hung, "Singapore's learning sciences lab: seeking transformation in ICT enabled pedagogy," Education, technology $R \& D$, vol. 52, no. 4, pp. 91-115, 2004.

[8] S. Sridhar, "E-Government - A proactive participant for e-learning for higher education," Journal of American Academy of Business, vol. 7, no. 1, pp. 258-268, 2005.

[9] U. Dixit, "The use of ICT in teacher training: Nepal's experience," in Proc. 13th UNESCO-APEID International Conference on Education, Hangzhou, China, 15-17 November 2009.

[10] A. J. Ramos, G. Nangit, A. I. Range, and J. Trinona, "ICT enabled distance education in community development in the Philippines," Distance education, vol. 28, no. 2, pp. 213-229, August 2007.

[11] M. Taylor, "Access and support in the development of a visual language: arts education and disabled students," International Journal of art and design education, pp. 325-333, 2006.

[12] M. Wild, "Screen or page: will the use of computer aided education improve phonological skills in year 1 classes?" Education Journal, vol. 80, pp. 27-28, 2004.

[13] UGC, Higher education in India, Strategies and Schemes during Eleventh Plan Period (2007-2012) for Universities and Colleges. Technical report, University Grant Commission, New Delhi, 2011.

[14] AICTE, Annual report, 2011-2012, Technical report, AICTE, New Delhi, 2012.

[15] K. Kannan and K. Narayanan, "Model and Learner Feedback for a Large Scale Technology Enabled Teacher Training Program," in Proc. IEEE International conference on Technology for Education, July 14-16, 2011, Chennai, India, 2011.

[16] NMEICT. (2013). National Mission on Education through ICT, Ministry of Human Resource Development, Government of India. [Online]. Available: http://www.sakshat.ac.in/.

[17] Y. Wang, N. S. Chen, and M. Levy, "The design and implementation of a holistic training model for language teacher education in a cyber face-to-face learning environment," Computer and Education, vol. 55, no. 2, pp. 777-788, 2010.

[18] A. E. Adem, "Teacher training through distance education: IICBA's experience," Africa education review, vol. 6, no. 1, pp. 174-184, 2009.

[19] A. Young et al., "Teacher Education Programmes Delivered at a Distance: An Examination of Distance Student Perceptions," Teaching and Teacher Education, vol. 24, pp. 601-609, 2008.

[20] H. Moeini, "Identifying Needs: A Missing Part in Teacher Training Programs," International Journal of Media Technology and Lifelong Learning, vol. 4, no. 1, pp. 1-12, 2008.

[21] X. Zhang and S. Hung, "Integrating of the high-tech and low-tech in distance teacher training in China: An insight from the case of Jiagsu Radio and Television University," International Review of Research in Open and Distance Learning, vol. 8, no. 1, pp. 1-14, 2007.

[22] G. L. Arora and S. Pandey, "Teachers' continuing education: Shifting focus on distance mode," Indian Journal of open learning, vol. 7, no. 3, pp. 255-265, 1998.

[23] IGNOU. (2013). [Online]. Available: www.ignou.ac.in/

[24] B. Bhattacharya, "Engineering education in India - the role of ICT," Innovations in Education and Teaching International, vol. 45, no. 2, pp. 93-101, 2008.

[25] AVIEW. (2013). Amrita Virtual Interactive e-learning World - A multimedia e-learning platform. [Online]. Available: http://aview.amrita.ac.in.

[26] T10KT. (2013). Website for Train 10000 Teachers workshop. [Online]. Available: http://www.it.iitb.ac.in/nmeict/home.do.

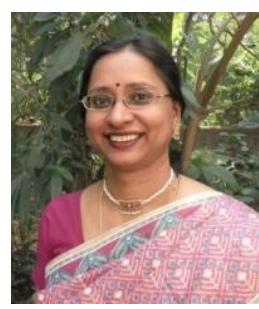

Kalpana Kannan holds a masters degree in management from University of Bombay, India in 1990 and an undergraduate degree in physics from University of Delhi, India in 1987. She is currently pursuing her doctorate in the Department of Humanities and Social Sciences at the Indian Institute of Technology Bombay. She is working as a senior project manager in the Department of Computer Science and Engineering, at the Indian Institute of Technology Bombay, Mumbai, India. She has over 15 years of experience at the managerial and administrative levels. Her research interests are in the areas of ICT enabled education, professional development of teachers and evaluation. She has presented papers in international conferences and has published her research in Journals and as book chapters. 


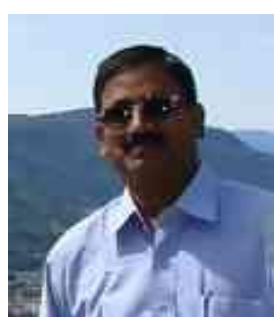

Krishnan Narayanan obtained his $\mathrm{PhD}$ in economics from the Delhi School of Economics, India and carried out Post-doctoral research at Institute of Advanced Studies United Nations University, Japan. He is currently institute chair professor and head, Department of Humanities and Social Sciences, Indian Institute of Technology Bombay, India. For the research studies in India, he was a recipient of the ICSSR fellowship at the Institute of Economic Growth His research interests span the areas of industrial economics, international business, Socio-economic aspects of ICT and Education, Economic impacts of Climate Change and Development Economics. He has a number of publications in the field of industrial competitiveness, technology transfer,
ICT, international trade and socio-economic impacts of Climate Change. The research journals in which he has published include Research Policy, Journal of Regional Studies, Technovation, Oxford Development Studies, International Journal of Energy Economics and Policy, and Economic and Political Weekly. Two of his recent publications include edited books on Indian and Chinese Enterprises: Global Trade, Technology, and Investment Regimes, and Human Capital and Development: The Indian Experience (both jointly edited with N.S. Siddharthan) published by Routledge and Springer, respectively. He has guest edited special issues of reputed journals. 